\title{
The role of a blue ocean strategy on performance evaluation
}

\author{
Mojtaba Tabari $^{\mathrm{a}^{*}}$ Mehrdad Ziabari $^{\mathrm{b}}$, Mona Radmard ${ }^{\mathrm{c}}$ and Mahdiyeh Radmard ${ }^{\mathrm{d}}$
}

\author{
${ }^{a}$ Public Management Group, Department of Management, Qaemshahr Branch, Islamic Azad University, Qaemshahr, Iran \\ ${ }^{b}$ Business Administration Group, Industrial Management Institute, Sari, Iran \\ ${ }^{c}$ Public Administration Group, Department of Management, Qaemshahr Branch, Islamic Azad University, Qaemshahr, Iran \\ ${ }^{d}$ Department of Business Management, Babol Branch, Islamic Azad University, Babol, Iran \\ C H R O N I C L E \\ A B S T R A C T
}

Article history:

Received February 252014

Accepted 17 July 2014

Available online

July 242014

Keywords:

Blue ocean

Red ocean

Value innovation

Balanced scorecard

\begin{abstract}
This paper develops a balanced scorecard (BSC) in order to prepare a comprehensive tool for performance evaluation. In this way, an experimental test is conducted in the Resorts of Ramsar Green City located in the north of Iran, in which the factors of a blue ocean strategy influence on the dimensions of the BSC. The sample number of this study consists of 90 managers and experts of the employees who work for Resorts of Ramsar Green City. The acquired data are analyzed with using the t-test. The obtained results show that the blue ocean strategy changes in the objects and the scales of the BSC.
\end{abstract}

\section{Introduction}

Today management machine has forced the bad-tempered, stubborn and careless human to follow standards and rules, which also kills innovation. In today's world, there is not any time for depending on the previous glories, and organizations need to strategic changes more than before. Today, human has increased his/her freedom with the help of removing limiting barriers in some fields, such as calculation, distance, time and ability. In other words, with more controlling on materials, energy and information, people have obtained a vaster choice in various fields of the life. In today's stormy world, the existence of a strategic thought in organizational levels is very important. May be heavy strategic planning have had no effectiveness any more due to the rate of environmental changes and it should be replaced by a systematic and applicable method that can lead to strategic movements in a short time. Most of those groups who engage in conducting the 21 century projects believe that our world is changing so continuous that it has never been like that in the past. Since these changes are occurring in the least time period, so we can freeze most data for conducting a long-term planning.

\footnotetext{
*Corresponding author.

E-mail addresses: mo_tabari@yahoo.com (M. Tabari) 
Radmard (2012) argued that in today's complex business most organizations must be able to learn how to cope with continuous change in order to be successful. In this changing environment, the need for adequate design, implementation and use of performance measurement systems, is bigger than ever. Organizations space becomes more dynamic and more uncertain ever-increasingly and managing the organization in such circumstances needs to have an organizational innovation and a strategic attitude (Chytas et al., 2011). According to these evolutions, control principle as an integral and important part of the management helps organizations reach their objectives. The balanced scorecard (BSC) method is an idea for controlling the organization based on its objectives and strategies. In addition, some researchers have suggested an expanded criterion for designing measurement and performance evaluation systems (Ebne Rasoul \& Rezaee, 2004).

Despite different methods, according to research, it is necessary to expand research about performance evaluation. In this way, our main objective is to develop a BSC to prepare a comprehensive tool for performance evaluation. During the past 25 years, the main focus of strategic thoughts was on the competitive strategies and the subject of competition has been in the center of strategy formulation methods. In the next step, our objective is that the blue ocean strategy becomes systematic and applicable as much as the competition in the known markets' waters. In such space, applying the blue ocean strategic thought helps organizations prevent from struggling and fighting on market share by introducing new markets. The relative low competition power of Iranian Companies and lack of development on some concepts about free economy have created the necessity of moving towards introducing an un-competitive space and maximum enjoyment from market capacities become an inevitable matter for organizations' survival. Therefore, entrance of this model in strategic management of Iranian commercial agencies may provide a good ground for national and industrial development. Note that setting a good applicable model for performance evaluation cannot be done easily and without considering academic research and a comprehensive study with experiences of other experts in management science.

\section{Literature review}

\subsection{Blue ocean strategy}

New attitudes in strategic management suggest that by value innovation, we can introduce a market in which people can do their works without any competitor and also make profit along a continuous growth. Kim and Mauborgne (2005a) introduced the idea of "Blue Ocean" in 2004. In the space of Blue Ocean, there is a concept named "Value innovation", which questions the traditional thought of the substituting relationship to Value-Cost. Value innovation occurs in a place, in which the company's measures and managerial decisions lead to both improving the cost structure and increasing the value available to the buyers. The creators of blue oceans surprisingly did not use the competition as their benchmark (Haeriyazdi \& Afsharjalili, 2010). Creating a successful blue ocean strategy requires a new mindset, analysis, and a measure of creativity (Kim \& Mauborgne, 2005a). By changing their strategic thinking and using a systematic approach, the authors showed how companies could reach beyond existing demand to find a blue ocean of new market space with the potential for huge profits and growth (Pitta, 2009). The strategy canvas is both a diagnostic and an action framework for building a compelling blue ocean strategy (Kim \& Mauborgne, 2005b). It serves two purposes: First, it captures the current state of play in the known market space. This allows us to understand where the competition is currently investing, the factors the industry currently competes on in products, service, and delivery, and what customers receive from the existing competitive offerings on the market. The strategy canvas clearly depicts the traditional factors that influence on competition among industry players, as well as new factors that lead to creation of new market space and that shift the strategy canvas of an industry (Kim \& Mauborgne, 2005a).The strategy canvas enables companies to see the future in the present. To achieve this, companies must understand how to read value curves. Embedded in the value curves of an industry is a wealth of 
strategic knowledge on the current status and future of a business. The strategy canvas has three things. First, it shows the strategic profile of an industry by depicting very clearly the factors (and the possible future factors) that affect competition among industry players. Second, it shows the strategic profile of current and potential competitors, identifying which factors they invest in strategically. Finally, it shows the company's strategic profile - or value curve-depicting how it invests in the factors of competition and how it might invest in them in the future. When a company's value curve zigzags, it signals that the company does not have a coherent strategy (Kim \& Mauborgne, 2005c).

\subsection{Balanced Scorecard (BSC)}

A study conducted by USA management accountants institute shows that BSC was an initiator system for strategic management and firm's performance and it has left behind quality management (e.g., Malcolm Baldrige, European Quality Management Institute, and six sigma) or financial management (economic value added). Strategy formulation methodologies consist of five powers of Michael porter, competitive orientation frame, source-based approach, basic competences, interventionist strategies and blue ocean strategy. Scenario-based programming, dynamic simulation and war-gaming are used for evaluating the power of these strategies (Mohammadnezhad \& Nasrollahzadeh, 2008). Kaplan and Norton tried to evaluate and measure the productivity by using Peter Dracker theories, finally, they designed balanced scorecard model (Alvani et al., 2005). Kaplan and Norton (1983) suggested the BSC in four financial aspects: customer, internal processes, learning and growth in their general model. After that, most of researchers have considered these four aspects as unchangeable factors in balanced evaluation. The BSC has been confirmed that the number of these aspects can be different based on the organization's interesting concepts and fields related to fulfillment of the strategy. Fig. 1 depicts the BSC Framework.

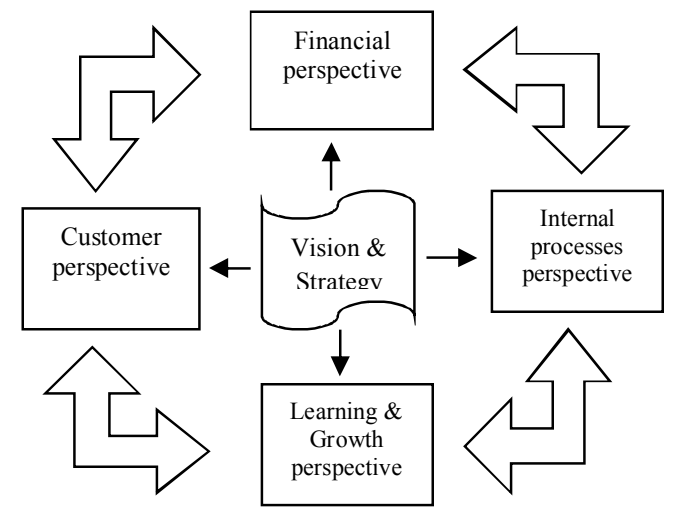

Fig. 1. BSC Framework

\subsection{Necessity of examining a blue ocean strategy in the BSC model}

One of the most common mistakes in employing the more analytical strategic tools is that people feel most inclined to use them to describe the current state (or even recent historic state) of the market and firm, but often fail to use them to evaluate the possible future states of the world. Working on the assumption that the future is, in fact, the most important time period for a business attempting to construct its competitive strategy, this seems to be an important oversight. In fact, the real development of strategy requires us to pay attention at both the current and future states and then apply the tools at our disposal in order to bridge the gap between the two and make our organizations competitive in the future world (Pugh \& Bourgeois, 2011). Difficulties appear by implementation of a strategy in daily life. Especially on the middle management level and on other employees who are every day in contact with customers. Firms operating in fast changing business climate must pay attention to nonfinancial performance indicators determined by BSC and value-based approach 
derived from a critical success factors (CSF) approach. An interesting question is how to effectively put these two approaches together. How company can pick up emerging strategies while implementing the current strategy? Is really the BSC able to bring the right performance indicators for both tasks at the same time? To find the right indicators is not often very easy. Market oriented critical success factors represents key to performance management system that provides information about changing customer needs and wants (Striss \& Vodak, 2007).

The Blue Ocean Strategy (BOS), developed by Kim and Mauborgne (2005a, 2005b, 2005c) was fashioned on the evaluation of the strategic moves of organizations over the past century created a leap in customer value through value innovation. It has been used to develop and expand markets into new, un-chartered waters, and has thus become the antithesis of traditional strategic management. Benchmarking is fundamental traditional technique utilized to compare one organization to another or to a standard (Becker, 2010). All the perspectives of the BSC are largely incorporated from the view point of the enterprise. Though the customer perspective involves the factors of offerings and relationships, these are taken-up in an implicit manner within the framework of customer satisfaction index. The customer factors are essential in evolving the strategy of the enterprise. The Blue Ocean strategy deals with the customer factors associated with the offerings as central focus of the strategy. Thus, the framework of the BSC needs a re-look to incorporate the customer factors along with the enterprise factors in an explicit manner to enrich the strategy formulation and implementation processes (Sushil, 2008).

This paper takes a reverse approach and utilize the blue ocean technique of the strategy canvas in evaluating performance measurement while linking in the balanced scorecard within the framework of both traditional strategy and the blue ocean strategy to formulate a more complete model of developing and effectively evaluating the corporate and business level strategies, designed to take the organization into a new era of prosperity and expansion. BOS utilizes the approach of developing a strategic canvas, a map of key performance indicators (KPI's) within an industry and identifies how your company compares to the competition. This straight forward approach allows management to easily see the typical results which generally tends to show convergence strategies used by organizations, as management of different companies' benchmark against each other and target the industry leader on the same key performance indicators (Becker, 2010). The BSC can align the organizations internal resources and processes to effectively determine the ability of the organization to pursue a blue ocean, as well as effectively be used to evaluate the implementation of the BOS (Becker, 2010). The BSC is advocated to be balanced on multiple fronts (Sushil, 2008). It is through this combination of internal evaluation of the effective utilization of the resources of the company and the evaluation of the development and implementation of the BOS that a company will be able to determine the impact of the new strategy on the organization and the ability to fully coordinate those resources to maximize the value innovation proposed in the BOS framework (Becker, 2010).

Continuity and change are hallmarks of strategic thinking all through. The strategic management of change can be better leveraged with clear understanding of continuity of the organization and consciously managing the vital and desirable areas of continuity along with change. The BSC framework is almost silent on this important dimension of the strategy. It requires addressing the forces of both continuity and change operating on an enterprise. In the volatile business environment, the reactive drivers linked with the prevailing 'situation' become equally important. There is a need to incorporate 'situation' drivers of strategy in the Balanced Scorecard. This will make the system dynamic with change in situation; both external and internal situation elements would be relevant to be addressed. Thus, there is a pressing need to reformulate the strategic management system to balance multiple concerns that are not adequately addressed in the current framework of the BSC. Moreover, the strategic management system is not supposed to only act as a strategy deployment tool, rather it should support the whole cycle of strategy formulation and execution and thus there is a need of a strategy game card rather than only a scorecard. Furthermore, the strategy game card is supposed 
to evolve as a generalized game card for Business/Government/Projects and many more types of organizational forms (Sushil, 2008).

\subsection{Reviewing}

Examining on credible scientific sites and journals shows that blue ocean strategy has been applied for several years in Europe, USA and Asia. This strategy as a hidden hand has guided three industries of USA (e.g., automobile, computer, cinema) to introduce new products and services for many years. Finally, Kim and Mauborgne (2005) introduced it to the management world. Becker (2010) conducted a project by the name of "Using Blue Ocean Strategy in Performance Evaluation". In this project, he showed that blue ocean strategy was a special and efficient method in organization. It prepared the way for organization to access to new markets and go ahead of its commercial rivals; but not by competing with them, rather by making unbalanced the competition trend. This project follows a contradictory attitude and tries to make a relationship between blue ocean strategy and balanced scorecard for developing a precise model from effective formulation and evaluation of commercial strategies at company level. Radmard (2012) presented a case study from an Iranian dairy producer named Amol's Kaleh Company. In that project, the researcher tried to examine the relationship between blue ocean strategy and BSC. The primary objective was to develop a BSC model in order to introduce a comprehensive tool for performance evaluation. In that way, he did an experimental test in the firm and reported that blue ocean strategy could cause a change in objectives and scales of customer, financial, learning and growth and business internal processes. Pitta (2009) described a mental strategic attitude used for developing products. This project is among case studies, which studied on clothing retailing industry. This case study described one attitude for preventing from risky and dangerous competition and tried to find a new market space. The author described a process in which the company reached to innovation. Parvinen at al. (2011) conducted a survey on awareness, action and context-specificity of Blue Ocean Practices in Sales Management. Kim et al. (2008) conducted a project as a strategy for third-party logistics systems and applied the blue ocean strategy for a case study.

\section{Research Questions}

Regarding to the conceptual model of our project, research questions are as follows:

1. Does the blue ocean strategy cause a change in objectives and scales of internal processes perspective?

2. Does the blue ocean strategy cause a change in objectives and scales of learning and growth perspective?

3. Does the blue ocean strategy cause a change in objectives and scales of customer perspective?

4. Does the blue ocean strategy cause a change in objectives and scales of financial perspective?

\section{Methodology}

The present study is an application research in terms of present and it is among descriptive research and field studies in terms of a data gathering manner through measuring methodology. In designing research questions, we try to present them as simple and clear. Based on the considered variable, questionnaire had 92 questions and items were measured based on 5-point Likert scales anchored by "strongly disagree" and "strongly agree". For assessing the reliability of research question, we pretest one initial sample consisted of 15 questions, then we calculated the validity coefficient with using the obtained data by Chronbach alpha method, this coefficient was determined as 0.88 . In general, the obtained alpha is higher than 0.7 , which suggested that our questionnaire is reliable. We use experts and professors' ideas for assessing the validity. In this step, we do some reforms by various interviews and obtaining ideas from the mentioned persons and thereby we assure that our 
questionnaire assesses the right characteristic. Our statistic universe consists of board of directors and experts of the Resorts of Ramsar Green City in 2013. The sample size is calculated as follows,

$$
n=\frac{N \times z_{\alpha / 2}^{2} \times p \times q}{\varepsilon^{2} \times(N-1)+z_{\alpha / 2}^{2} \times p \times q},
$$

where $N$ is the population size, $p=1-q$ represents the yes/no categories, $z_{\alpha / 2}$ is CDF of normal distribution and finally $\varepsilon$ is the error term. Since we have $p=0.5, z_{\alpha / 2}=1.96$ and $N=117$, the number of sample size is calculated as $n=90$.

\section{Research results}

\subsection{Descriptive results}

In our survey, all participants were male, in terms of education, 74.7 percent had a B.A and 5.4 percent had M.A and 0.9 percent had a doctorate. In terms of age, 17.1 percent were between 31 and 40 years old, 35.1 percent were between 41 and 50 and 28.8 percent were older than 50 .

\subsection{Inferential results}

Table 1 shows some basic statistics associated with internal process including mean and standard deviation. In addition, Table 2 shows the results of $t$-student test on the effect of internal process.

Table 1

Results of descriptive statistics related to the internal processes

\begin{tabular}{ccccc}
\hline \multirow{3}{*}{ Internal Processes } & $N$ & One-Sample Statistics & Std. deviation & Std. error mean \\
\cline { 2 - 5 } & 90 & 4.0449 & .33567 & .03538 \\
\hline
\end{tabular}

\section{Table 2}

Results of t-test related to the first question

One-Sample Test $($ Test Value $=3)$

\begin{tabular}{|c|c|c|c|c|c|c|}
\hline \multirow{3}{*}{$\begin{array}{c}\text { Internal } \\
\text { processes }\end{array}$} & \multirow{2}{*}{$t$} & \multirow{2}{*}{ df } & \multirow{2}{*}{ Sig. (1-tailed) } & \multirow{2}{*}{ Mean difference } & \multicolumn{2}{|c|}{$95 \%$ confidence interval of the difference } \\
\hline & & & & & Lower & Upper \\
\hline & 29.532 & 89 & .000 & 1.04493 & .9746 & 1.1152 \\
\hline
\end{tabular}

Table 2 presents the $t$-statistic value is 29.532 and $p$-value is 0.000 . Therefore, at the significance level of $5 \%$, there is not any reason to reject the first hypothesis; i.e. the blue ocean strategy causes a change in objectives and scales of the learning and growth aspect. The obtained results of descriptive statistics associated with the learning $\&$ growth processes are shown in Table 3. Table 4 shows the $t$ statistic value is 13.408 and $p$-value is 0.000 . Therefore, at the significance level of $5 \%$, there is not any reason to reject the hypothesis (1); i.e., the blue ocean strategy causes a change in objectives and scales of the learning and growth aspect.

Table 3

Results of descriptive statistics related to the learning \& growth aspect

\begin{tabular}{ccccc}
\hline & \multicolumn{5}{c}{ One-Sample Statistics } \\
\hline \multirow{2}{*}{ Learning \&growth } & $\mathrm{N}$ & Mean & Std. deviation & Std. error mean \\
& 90 & 3.7831 & .55406 & .05840 \\
\hline
\end{tabular}


Table 4

Results of t-test related to the second question

\begin{tabular}{lcccccc}
\hline \multicolumn{6}{c}{ One-Sample Test (Test Value $=3)$} \\
\hline \multirow{2}{*}{$\begin{array}{l}\text { Learning } \\
\text { \&growth }\end{array}$} & $t$ & Df. & Sig. (1-tailed) & Mean difference & $\begin{array}{c}95 \% \text { confidence interval of the difference } \\
\text { Lower }\end{array}$ & Upper \\
\cline { 2 - 7 } & 13.408 & 89 & .000 & .78309 & .6670 & .8991 \\
\hline
\end{tabular}

The obtained results of descriptive statistics related to the customer processes are shown in Table 5 . Table 6 shows the $t$-statistic value is 15.893 and $p$-value is 0.000 . Therefore, at the significance level of $5 \%$, there is no any reason to reject the hypothesis (1); i.e., the blue ocean strategy causes a change in objectives and scales of the customer aspect.

Table 5

Results of descriptive statistics related to the customer aspect

One-Sample Statistics

Customer

$\begin{array}{cccc}N & \text { Mean } & \text { Std. Deviation } & \text { Std. Error Mean } \\ 90 & 3.8174 & .48792 & .05143\end{array}$

\section{Table 6}

Results of $t$-test related to the third question

\begin{tabular}{ccccccc}
\hline & \multicolumn{7}{c}{ One-Sample Test (Test value $=3)$} \\
\hline \multirow{3}{*}{ Customer } & $t$ & Df. & Sig. (1-tailed) & Mean difference & $\begin{array}{c}95 \% \text { confidence interval of the difference } \\
\text { Lower }\end{array}$ & Upper \\
\cline { 2 - 7 } & 15.893 & 89 & .000 & .81739 & .7152 & .9196 \\
\hline
\end{tabular}

The obtained results of descriptive statistics related to the financial processes are shown in Table 7 . Table 8 presents the $t$-statistic value is 15.148 and $p$-value is 0.000 . So, at significance level of $5 \%$, there is no any reason to reject the hypothesis (1); i.e., the blue ocean strategy caused a change in objectives and scales of financial aspect.

Table 7

Results of descriptive statistics related to the financial aspect

\begin{tabular}{ccccc}
\hline \multirow{3}{*}{ Financial } & \multicolumn{5}{c}{ One-Sample Statistics } \\
\cline { 2 - 5 } & $N$ & Mean & Std. deviation & Std. error mean \\
\hline
\end{tabular}

Table 8

Results of $t$-test related to the fourth question

\begin{tabular}{ccccccc}
\hline & \multicolumn{8}{c}{ One-Sample Test (Test Value $=3)$} \\
\hline \multirow{3}{*}{ Financial } & \multirow{2}{*}{$t$} & Df. & Sig. (1-tailed) & Mean difference & \multicolumn{2}{c}{$95 \%$ confidence interval of the difference } \\
\cline { 2 - 7 } & 15.148 & 89 & .000 & .90918 & Lower & Upper \\
\hline
\end{tabular}

\section{Discussion and Conclusions}

During the past few years, many firms have fought for competitive advantage, battled over market share, and struggled for differentiation (Kim \& Mauborgne, 2005b). They should consider customers' need and search for new markets by replacing "competitive advantage" with "value innovation" (Burke et al, 2008). Doing business in "blue oceans", and avoiding the blood flowing from the competitive war (the "red oceans") is apparently the new "must", or at least an objective to pursue. It certainly was a "technically" excellent marketing endeavor, based on the expedient of an original 
title, an intriguing subtitle, new labels for several old concepts and similar views expressed by other authors, an intelligent and well-targeted communication campaign, and the prestige of the sponsoring business schools (Gandellini \& Venanzi, 2011). Companies should evaluate their performance continuously in order to get informed about the market status. Here, BSC model can be a solution for problems resulted from performance evolution but it has some shortcoming and using blue ocean strategy can be a solution strategy. Thus, we tried to examine the effect of a blue ocean strategy on the BSC model. The analysis of our study data showed that blue ocean strategy could cause a change in objectives and scales of the BSC model.

\section{References}

Alvani, S.M., Mir Sepasi, N., Mojibi, T. (2005). Development of a balanced Scorecard model in the governmental section. Journal Pazhouheshgar, 5, 1-16.

Burke, A. E., Van Stel, A., \& Thurik, R. (2009). Blue ocean versus competitive strategy: theory and evidence. ERIM Report Series Reference No. ERS-2009-030-ORG.

Becker, H. (2010). Using blue ocean strategy in performance evaluation. International Journal of Strategic Management. 10(2).

Chytas, P., Glykas, M., \& Valiris, G. (2011). A proactive balanced scorecard.International Journal of Information Management, 31(5), 460-468.

Ebnerasoul, A., Rezaee, M. (2005). Application of the balanced scorecard for function evaluation. Modiriyate Farda, 2 [In Persian].

Gandellini, G., \& Venanzi, D. (2011). Purple Ocean Strategy: How To Support SMEs' Recovery. Procedia-Social and Behavioral Sciences, 24, 1-15.

Haeriyazdi, M., \& Afsharjalili, Y. (2010). Using the blue ocean strategy in information technology center (Magfa). Gozideye Modiriyat [In Persian].

Kaplan, R. S., \& Norton, D. P. (2004). Strategy maps: Converting intangible assets into tangible outcomes. Harvard Business Press.

Kim, W. C., \& Mauborgne, R. (2005a). Blue ocean strategy: How to create uncontested market space and make competition irrelevant. Harvard Business Press.

Kim. W.C, Mauborgne. R, (2005b). Blue Ocean Strategy, How to Create Uncontested Market Space and Make the Competition Irrelevant. Harvard Business School Press.

Kim, W.C. and Mauborgne, R. (2005c). Blue ocean strategy: from theory to practice. California Management Review, 47(3), 105-121.

Kim, C., Yang, K. H., \& Kim, J. (2008). A strategy for third-party logistics systems: a case analysis using the blue ocean strategy. Omega, 36(4), 522-534.

Mohammadnezhad, F., \& Nasrollahzadeh, H. (2008). The achievement of using balanced scorecard. Tadbir [In Persian].

Parvinen, P., Aspara, J., Hietanen, J., \& Kajalo, S. (2011). Awareness, action and context-specificity of blue ocean practices in sales management. Management Decision, 49(8), 1218-1234.

Pitta, D. (2009). Issues in a down economy: blue oceans and new product development. Journal of Product \& Brand Management, 18(4), 292-296.

Pugh, J., \& Bourgeois III, L. J. (2011). "Doing" strategy. Journal of Strategy and Management, 4(2), 172-179.

Radmard, M. (2012). Examining the role of the blue ocean strategy in balanced scorecard model (BSC); Case study: Amols' kaleh company. M.A thesis Islamic Azad university, Qaemshahr.

Striss, J., \& Vodak, J. (2007). Strategic control - performance management tool for increasing company competitiveness. Faculty of management Science and Informatics, University of Zilina.

Sushil, K. (2008). How Balanced is Balanced Scorecard?. Global Journal of Flexible Systems Management, $9(2 \& 3), 3-4$.

Thompson, K. R., \& Mathys, N. J. (2008). The Aligned Balanced Scorecard:: An Improved Tool for Building High Performance Organizations. Organizational dynamics, 37(4), 378-393. 